Avicenna Journal of Nursing and Midwifery Care - ISSN 2676-5748

\title{
The Effects of Sleep Hygiene Education on Fatigue and Sleep Quality in Hemodialysis Patients: A Quasi Experimental Study
}

\author{
Seyed Reza Borzou', Fahimeh Khavari", Leili Tapak ${ }^{3}$
}

1. Associate Professor, Department of Medical Surgical Nursing, School of Nursing and Midwifery, Hamadan University of Medical Sciences, Hamadan, Iran

2. MSc. Student in Nursing, Student Research Committee, School of Nursing and Midwifery, Hamadan University of Medical Sciences, Hamadan, Iran

3. Assistant Professor, Department of Biostatistics, School of Health, Hamadan University of Medical Sciences, Hamadan, Iran

\begin{tabular}{ll}
\hline Article Info & Abstract \\
\hline
\end{tabular}

Received: $\quad 2018 / 08 / 15$

Accepted: $\quad$ 2018/09/11

Published Online: 2019/03/22

DOI: 10.30699 /ajnmc.27.1.25

Original Article

Use your device to scan and read the article online

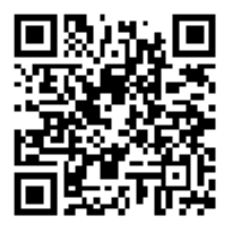

Introduction: Hemodialysis is one of the chronic diseases that has negative effects on all aspects of the patient's life. The quality of life of patients with hemodialysis is impaired due to the many problems and chronic nature of the disease. Also, fatigue is one of the common problems of these patients. The aim of this study was to evaluate the effect of sleep health education on the severity of fatigue and quality of sleep in hemodialysis patients in Hamadan.

Methods: In this quasi-experimental study, 60 hemodialysis patients were selected by available sampling from Besat (Intervention) and Beheshti (Control) hospitals. All samples completed the demographic checklist, Piper Fatigue scale and Pittsburgh Sleep Quality Index (PSQI). The control group received routine care and the intervention group, received sleep hygiene education face to face and by providing educational booklet in 3 consecutive dialysis sessions. After two months of training, sleep quality and fatigue intensity of the samples were checked. To analyze the data, SPSS software, descriptive and inferential tests were used.

Results: There were no significant differences between the intervention and control groups in terms of underlying variables. There was a significant difference between the control and intervention groups regarding quality of sleep and fatigue after sleep hygiene education $(P<0.001)$.

Conclusion: The study results showed that Sleep Hygiene Education had an important and decisive impact on the Fatigue and Sleep Quality in Hemodialysis Patients and holding educational courses in this field for patients can be useful.

Keywords: Sleep Hygiene, Fatigue, Sleep Quality, Hemodialysis Patient

Copyright (C) 2019, This is an original open-access article distributed under the terms of the Creative Commons Attribution-noncommercial 4.0 International License which permits copy and redistribute of the material just in noncommercial usages with proper citation. 
بررسى تأثير آموزش بهداشت خواب بر شدت خستكى و كيفيت خواب بيماران همودياليزى: مطالعة نيمدتجربى

\section{سيد رضا برزو'، فهيمه خاورى Г"، ليلى تإيا؟}

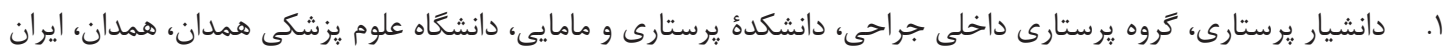

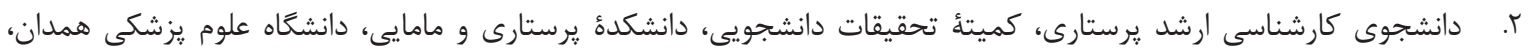

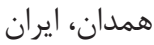

r. استاديار، كروه آمار زيستى، دانشكدة بهداشت، دانشكاه علوم يزشكى همدان، همدان، ايران

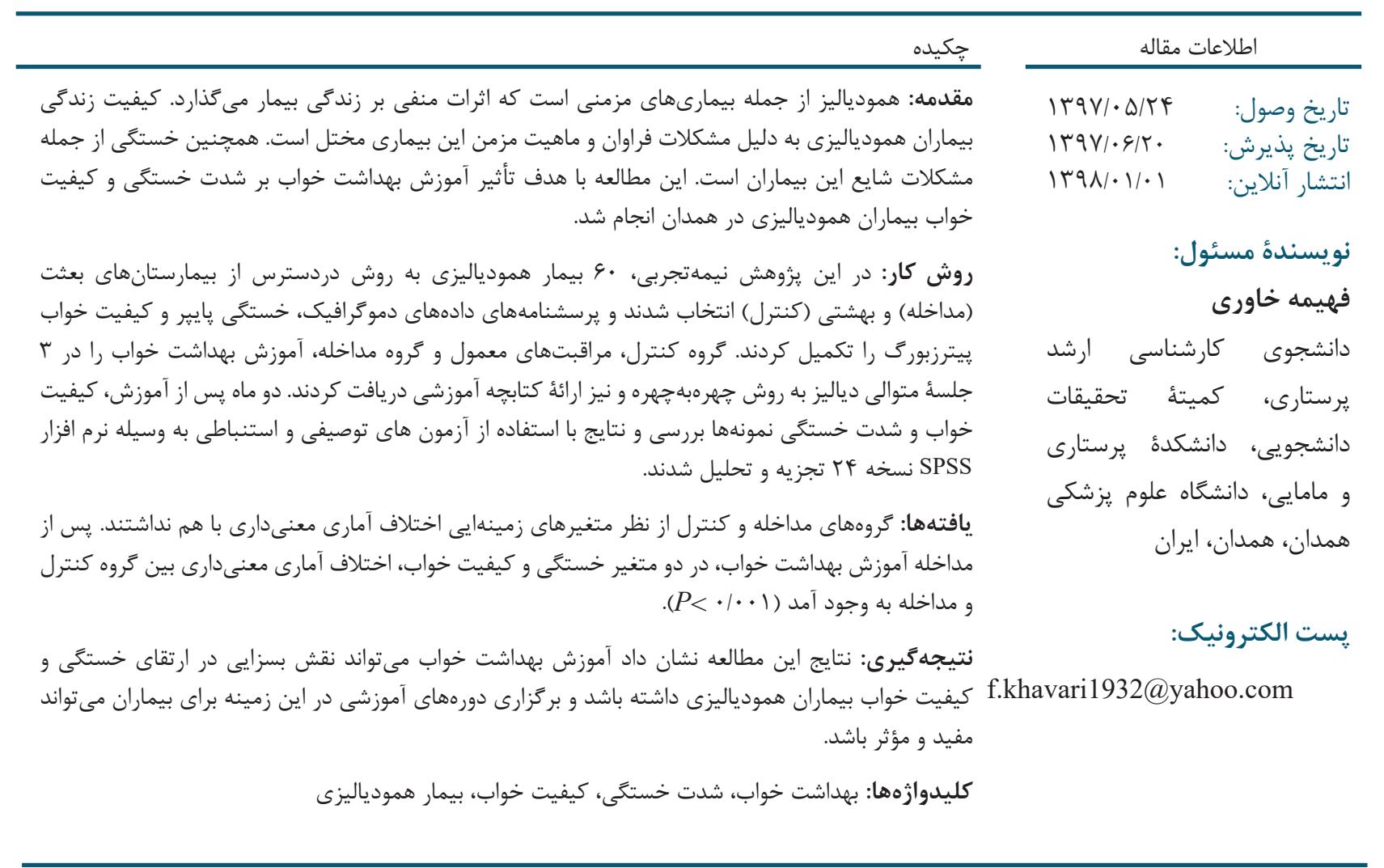

مقلمها

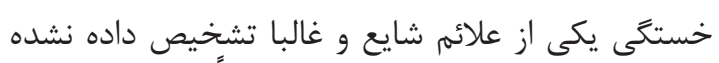

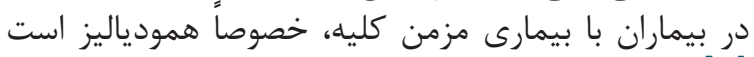

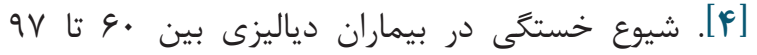

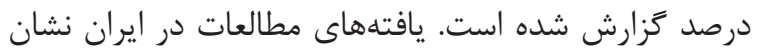

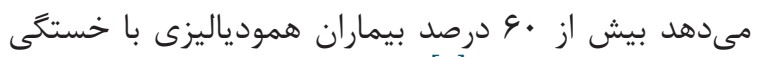

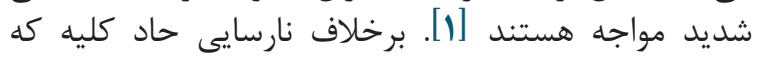

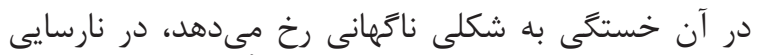

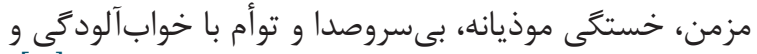

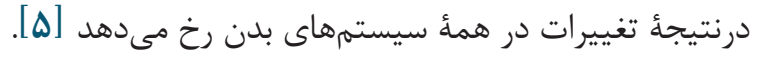

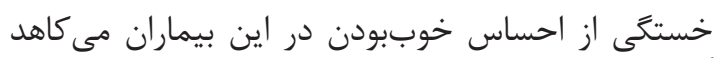

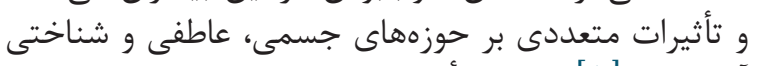

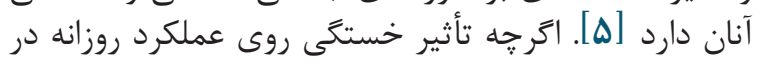

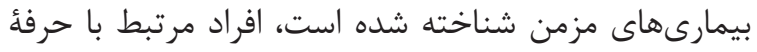

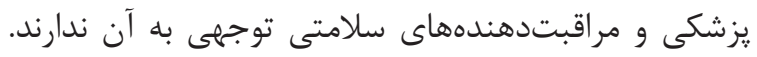

مرحلة انتهايى بيمارى كليه، بسيار وخيم است و تأثيرات

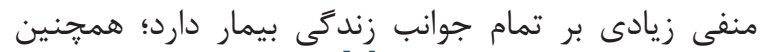

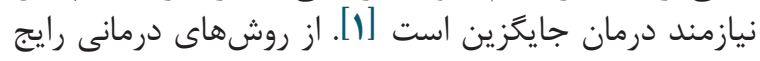

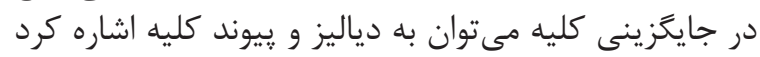

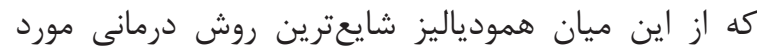

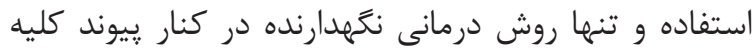

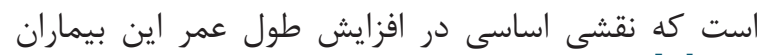

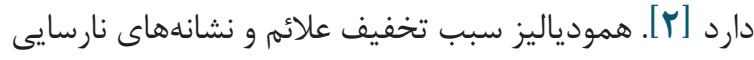

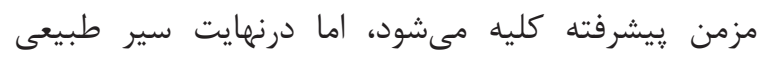

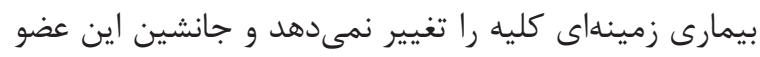

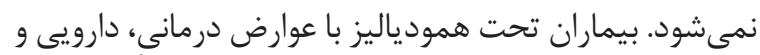

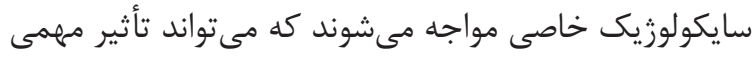

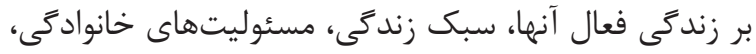

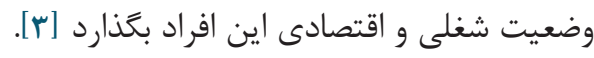




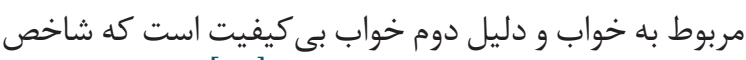

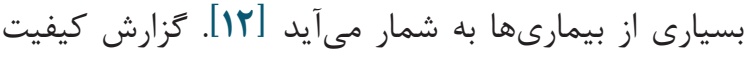

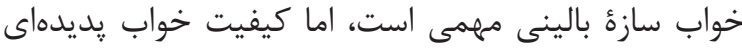

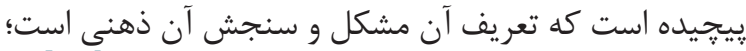

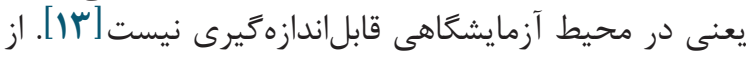

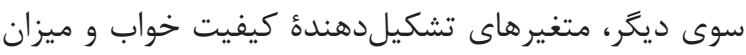

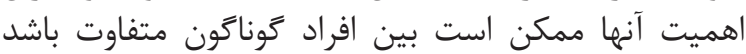

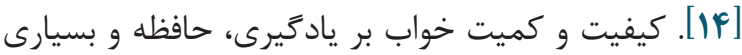

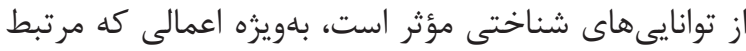

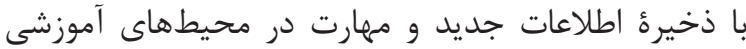

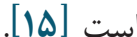

كيفيت خواب ضعيف يكى از علائم اصلى بى خوابى مزمن

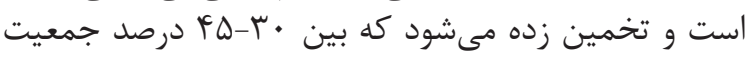

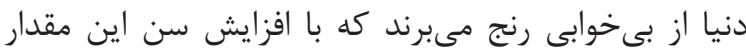

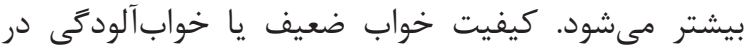

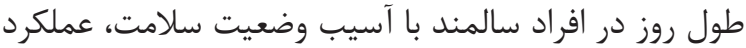

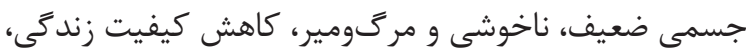

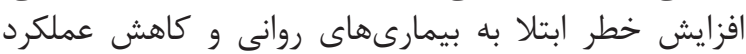

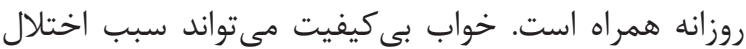

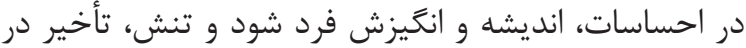

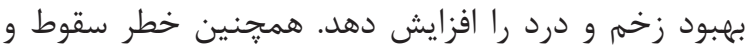

صدمات را بيشتر كند [آ [IT].

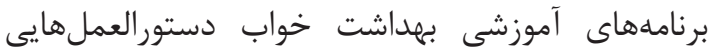

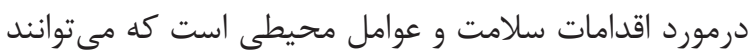

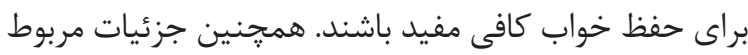

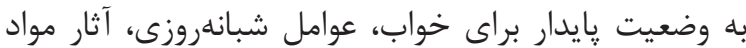

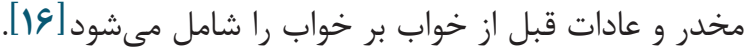

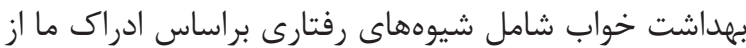

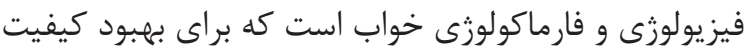

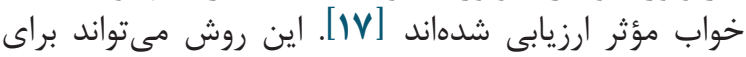

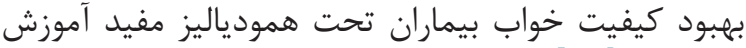

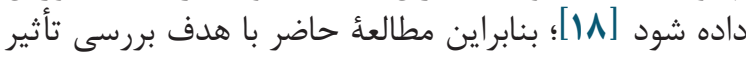

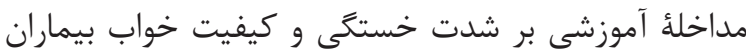
همودياليزى شهر همدان انجام شده است.

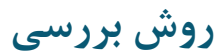

اين يزوهش نيمـهـجربسى دوكروهى است كه در سال

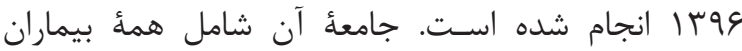

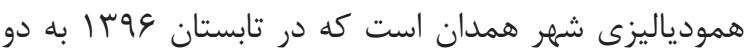

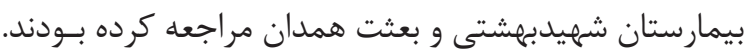

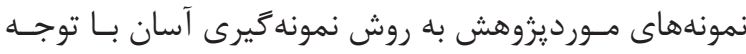

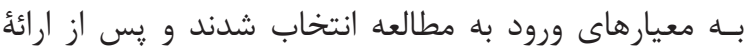

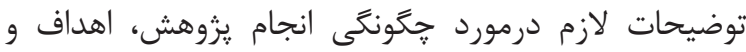

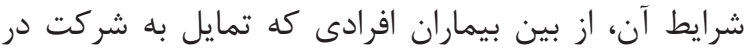

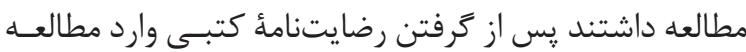

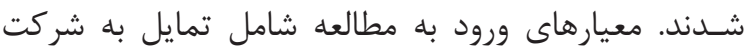

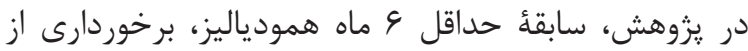

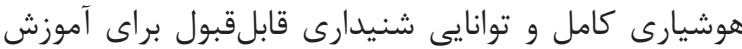

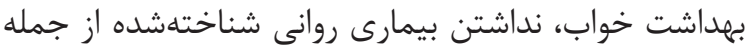

درمان بيشتر روى خود بيمارى متمركز مى شود و درواقع افر افراد

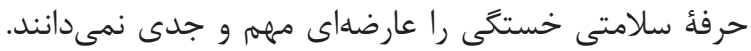

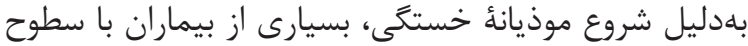

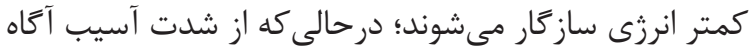

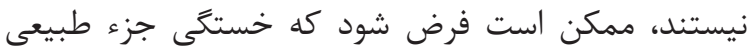

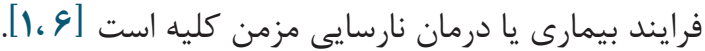

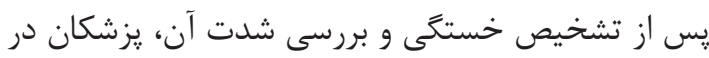

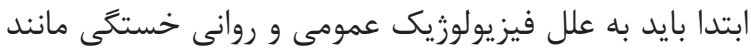

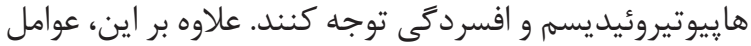

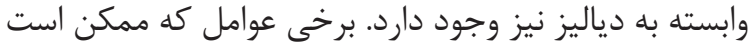

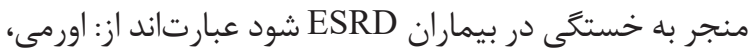

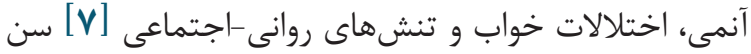

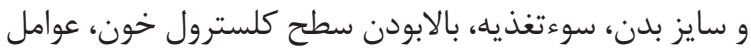

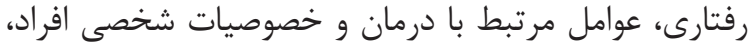

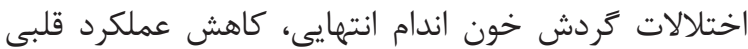

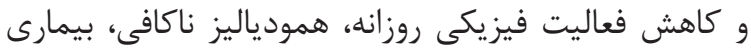

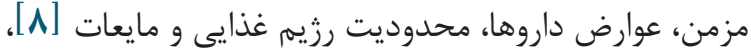

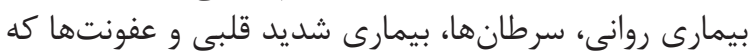
ممكن است منجر به مداخله شود [1].

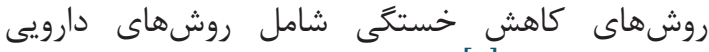

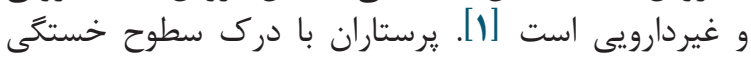

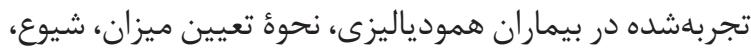

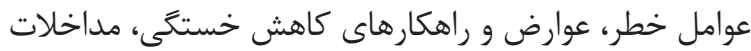

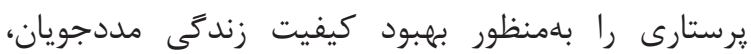

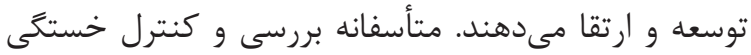

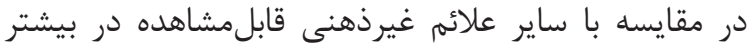

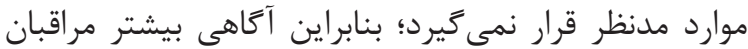

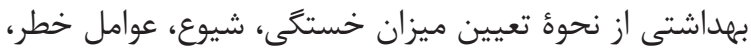

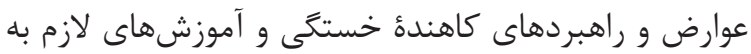

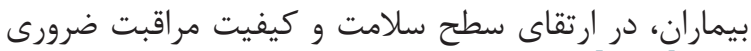

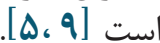

خواب عاملى مهمم در وضعيت سلامتى انسانهاست كه از

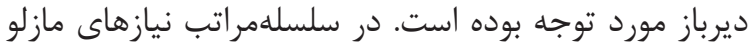

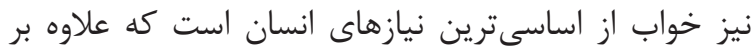

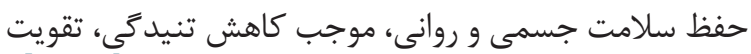

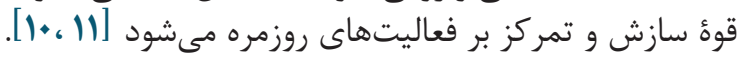

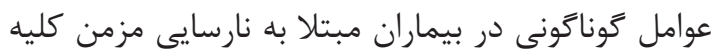

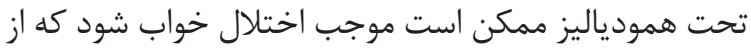

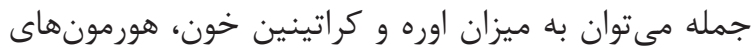

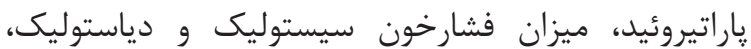

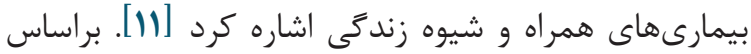

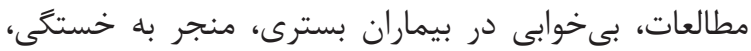

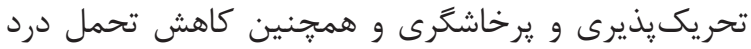

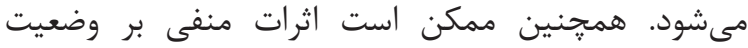

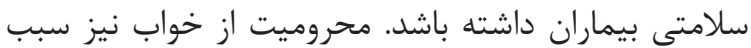

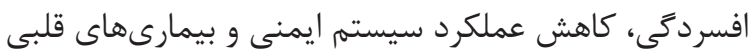

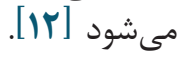
كيفيت خواب به دو دليل اهميت دارد: دليل اول شكايات 


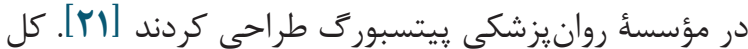

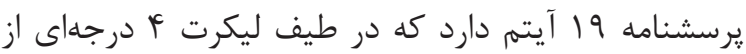

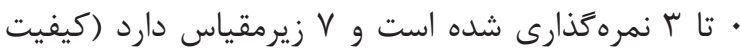

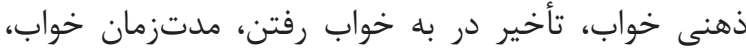

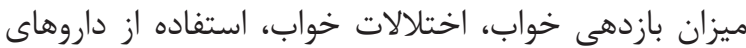

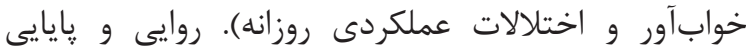

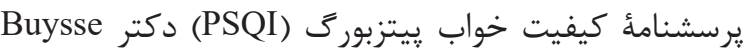

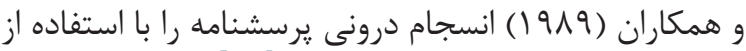

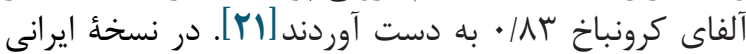

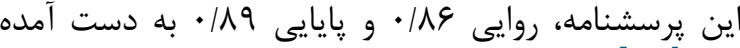

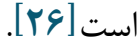

يس از انتخاب نمونهها و كروهبندى آنها در خروههاى

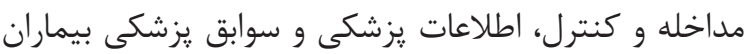

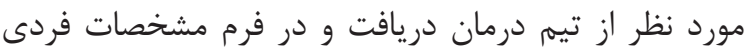

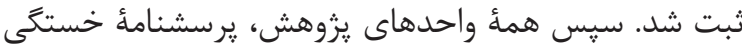

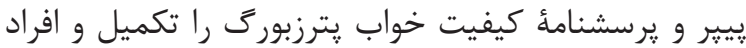

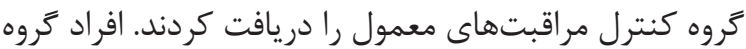

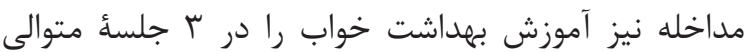

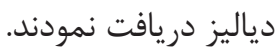

جلسؤ اول: معرفى و بيان اهداف يروهش، مفهوم و و اهميت خواب، عوامل مؤثر بر خواب و انواع اختلالات خواب؛

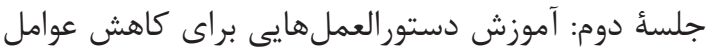

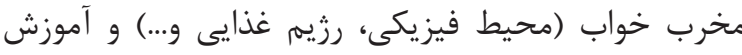
مداخلات رفتارى از جمله آرامسازى و تصويرسازى ذهنى فنى؛ جلسأ سوم: جمعبندى مطالب كَفتهشده، بازخورد از إز

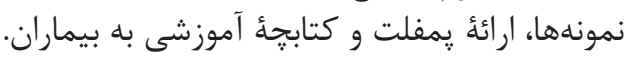

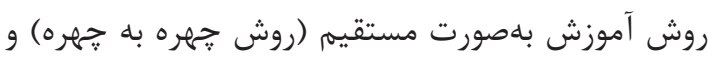

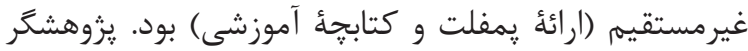

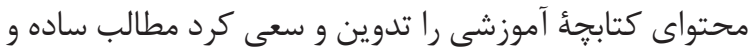

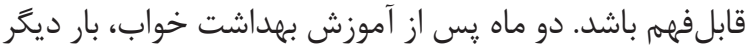

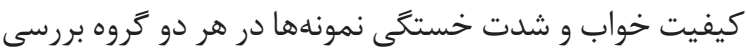

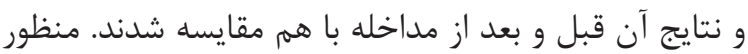

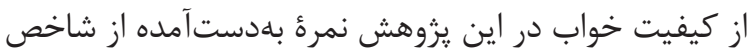

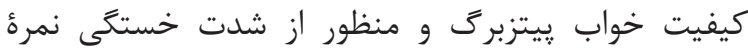

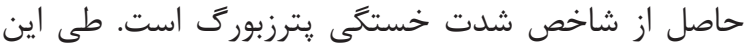

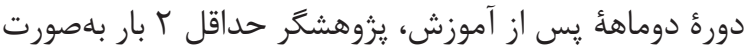

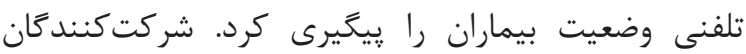

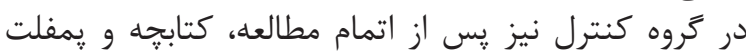

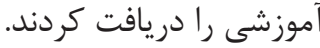

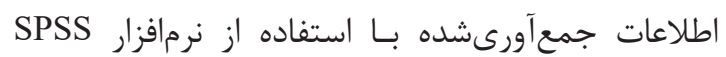

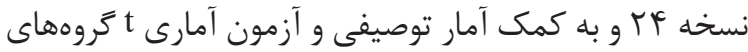

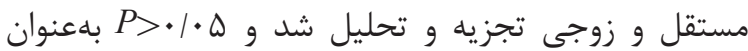

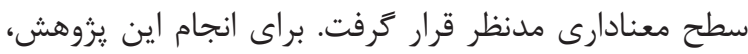

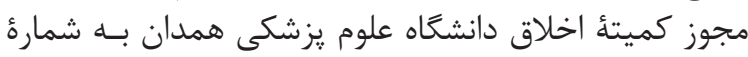
IR.UMSHA.REC.1396.34 دريافت شد شد.
اضطراب و افسردىى شديد و داشتن سواد خواندن و نوشتن

بود. معيارهاى خروج از اين يزوهش بـ به شرح زير است

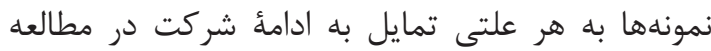

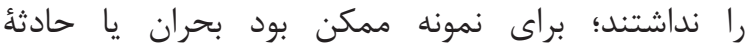

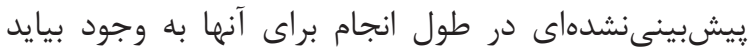

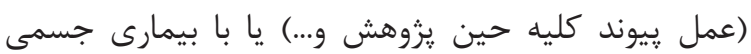

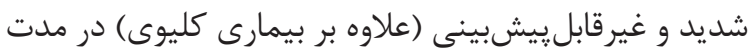

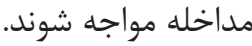

بهمنظور محاسبة حجم نمونه از رابطهُ زير استفاده شد:

$$
n=\frac{\left(z_{1-\frac{\alpha}{2}}+z_{1-\beta}\right)^{2}\left(\sigma_{1}^{2}+\sigma_{2}^{2}\right)}{\left(\mu_{1}-\mu_{2}\right)^{2}}
$$

بنابراين با توجه به سطح اطمينان آزمون لهو دروصد

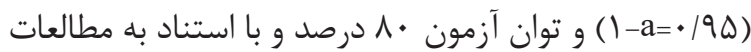

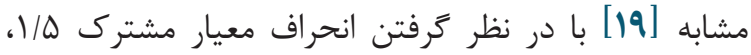

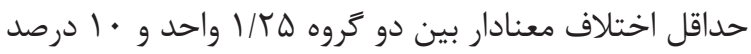

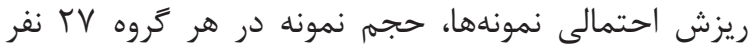

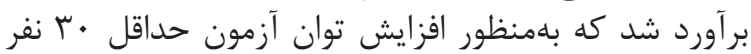

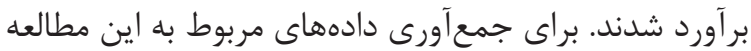
از سه ابزار زير استفاده شد: شدئ

\section{اطلاعات جمعيتشناختى اجتماعى و اطلاعات}

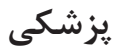

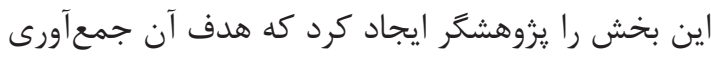

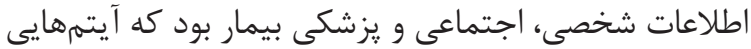

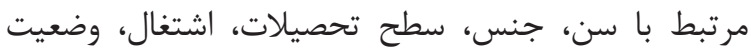

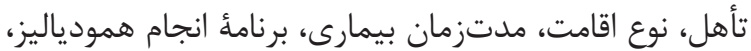

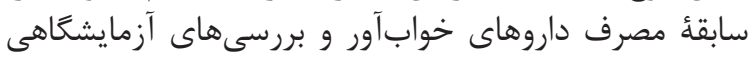

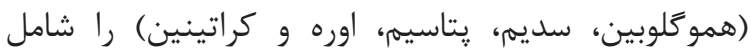

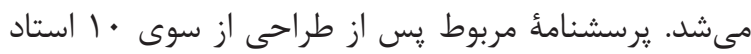

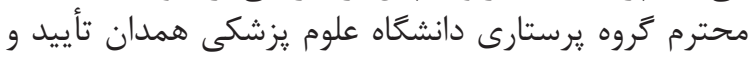

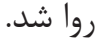

\section{ارزيابى خستكى (مقياس خستكى بِيِر)}

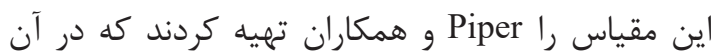

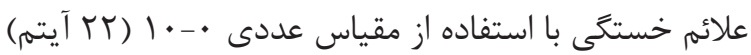

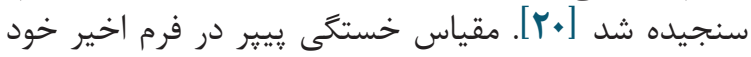

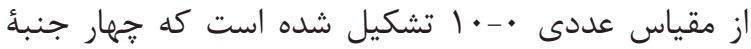

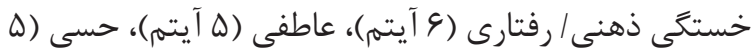

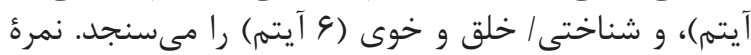

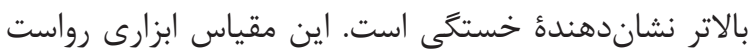

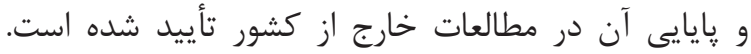

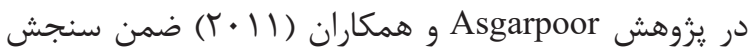

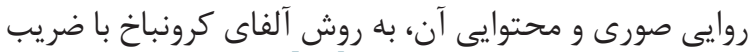

همبستخى 191/ • به تأييد رسيد [19]

\section{برسشنامة كيفيت خواب يترزبورى (PSQI)}

اين يرسشنامه را دكتر Buysse و همكاران در سال 1919 
در مؤلفئ شدت خستخى (حيطههاى رفتارى/ شدتى،

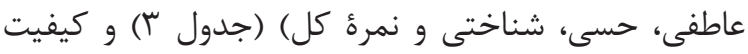

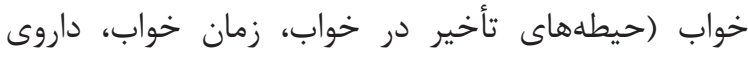

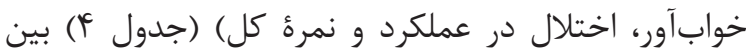

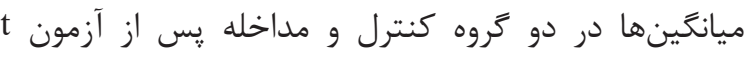

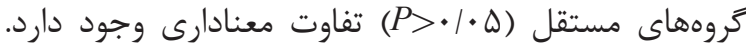

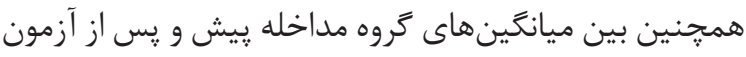

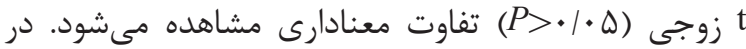

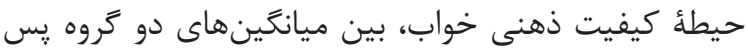

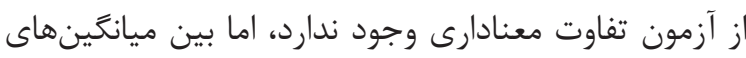

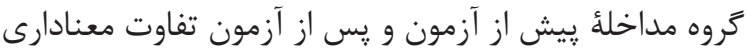

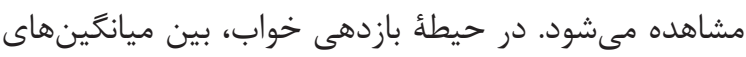

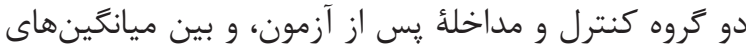

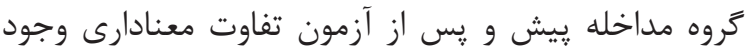

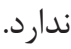

افراد مطالعُ حاضر بيشتر مرد بودند كه سواد خواندن

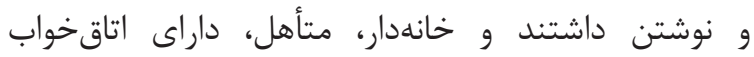

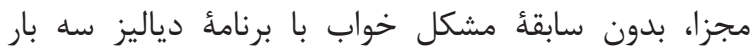

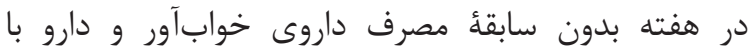

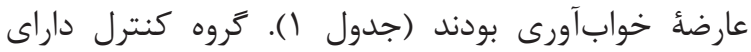
( وزن خشك س س/F

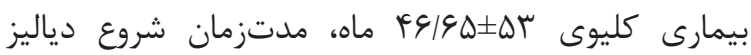
س • • ب א به درد س/R/A

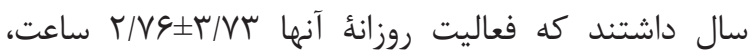

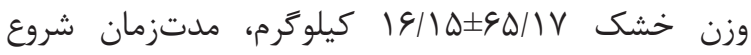
بيمارى كليوى

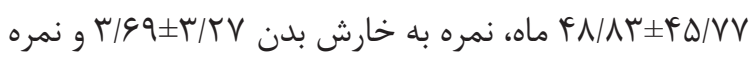
جدول ا. مشخصات دموكر افيك (متغيرهاى كيفى) بيماران در دو كروه مداخله و كنترل

\begin{tabular}{|c|c|c|c|c|c|c|c|}
\hline \multirow{2}{*}{ معنادارى سطح } & \multirow{2}{*}{ آمارئ آزمون } & \multicolumn{2}{|c|}{ مداخله } & \multicolumn{2}{|c|}{ كنترل } & \multirow{2}{*}{ تروه } & \multirow{2}{*}{ نام متغير } \\
\hline & & درصد & تعداد & درصد & تعداد & & \\
\hline \multirow{2}{*}{.1999} & \multirow{2}{*}{$\cdot / \cdots$} & $\forall \& / V$ & $\mid f / \cdot$ & $\varphi \& / V$ & $\mid \varphi / \cdot$ & 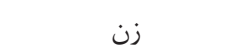 & \multirow{2}{*}{ جنسيت } \\
\hline & & 更 & 191. & س & 191. & مرد & \\
\hline \multirow{5}{*}{.1990} & \multirow{5}{*}{$1 / \wedge r$} & $r e / V$ & $\mid f /$. & $\varphi \& / V$ & $\mid \psi /$. & سواد خواندن و نوشتن & \multirow{5}{*}{ سطح تحصيلات } \\
\hline & & $1 \cdot 1 \cdot$ & $\mu /$ & $1 \% / r$ & $r /$. & ابتدايى & \\
\hline & & 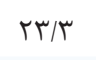 & $\mathrm{V} / \cdot$ & re/V & $\Lambda /$ & سيكل & \\
\hline & & 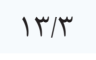 & $\boldsymbol{y} /$. & $9 / V$ & $r / \cdot$ & ديبلم & \\
\hline & & $9 / V$ & $r / \cdot$ & $9 / V$ & $r / \cdot$ & تحصيلات دانشگاهى & \\
\hline \multirow{5}{*}{. $19 \mathrm{Tr}$} & \multirow{5}{*}{ I/THF } & $F r / V$ & $\mid r / \cdot$ & $r \& / V$ & $\mid F / \cdot$ & خانهدار & \multirow{5}{*}{ اشتغال } \\
\hline & & $9 / V$ & $r / \cdot$ & $\varepsilon / V$ & $r / \cdot$ & كارمند & \\
\hline & & $9 / V$ & $r / \bullet$ & r & $1 / \cdot$ & بيكار & \\
\hline & & $r \cdot / \cdot$ & 41. & $r \& / V$ & $\Lambda /$ & بازنشسته & \\
\hline & & r & $\mathrm{V} / \cdot$ & $19 / V$ & $\Delta / \cdot$ & آزاد & \\
\hline \multirow{4}{*}{$\cdot / F \Delta F$} & \multirow{4}{*}{$r / 9 \cdot T^{r}$} & $19 / V$ & $\Delta / \cdot$ & $9 / V$ & $r / \bullet$ & 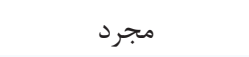 & \multirow{4}{*}{ وضعيت تأهل } \\
\hline & & 每 & $19 / \cdot$ & $19 / \cdot$ & $r M \cdot$ & متأهل & \\
\hline & & $19 / V$ & $\Delta / \cdot$ & $r M / V$ & $\mathrm{~V} / \cdot$ & بيوه & \\
\hline & & r/r & $1 / \cdot$ &.$/$ & $\cdot /$ & مطلقه & \\
\hline \multirow{2}{*}{.$/ 999$} & \multirow{2}{*}{$\cdot \cdots$} & $9 \cdot 1 \cdot$ & $r V / \cdot$ & $9 \cdot / \cdot$ & $r V / \cdot$ & بلى بلى & \multirow{4}{*}{ اتاقخواب مجزا } \\
\hline & & $1 \cdot 1$ & $\mu /$ & $1 \cdot 1 \cdot$ & $\mu /$ & خير & \\
\hline \multirow{2}{*}{.1999} & \multirow{2}{*}{$\cdot / \cdots$} & $r \cdot / \cdot$ & १/• & $r \cdot / \cdot$ & १/• & بلى & \\
\hline & & $\mathrm{V} \cdot / \cdot$ & $\langle\mathrm{l} / \cdot$ & $\mathrm{V} \cdot / \cdot$ & $r \mid / \cdot$ & خير & \\
\hline
\end{tabular}




\begin{tabular}{|c|c|c|c|c|c|c|c|}
\hline \multirow{2}{*}{ معنادارى سطح } & \multirow{2}{*}{ آمارة آزمون } & \multicolumn{2}{|c|}{ مداخله } & \multicolumn{2}{|c|}{ كنترل } & \multirow{2}{*}{ تروه } & \multirow{2}{*}{ نام متغير } \\
\hline & & درصد & ت تعداد & درصد & تعداد & & \\
\hline \multirow{2}{*}{.$/ 999$} & \multirow{2}{*}{$\cdot / \cdots$} & $V \cdot / \cdot$ & $r M \cdot$ & $v \cdot / \cdot$ & 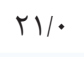 & هيج & \multirow{2}{*}{ شيوء حل مشكل خواب } \\
\hline & & $r \cdot / \cdot$ & १/• & $r \cdot / \cdot$ & १/• & استفاده از داروى خوابآور & \\
\hline \multirow{3}{*}{.$/ 9 r$} & \multirow{3}{*}{.$/ 191$} & $r \cdot / \cdot$ & $9 /$. & r & $\mathrm{V} / \cdot$ & يكبار در هفته & \multirow{3}{*}{ برنامةٔ انجام همودياليز } \\
\hline & & $r \cdot / \cdot$ & $9 /$. & $19 / V$ & $\Delta / \cdot$ & دو بار در هفته & \\
\hline & & $4.1 \cdot$ & $\mathrm{N} / \cdot$ & $9.1 \cdot$ & $\mid \mathrm{N} / \cdot$ & سه بار در هفته & \\
\hline \multirow{2}{*}{.$/ 999$} & \multirow{2}{*}{$\cdot / \cdots$} & $\Lambda \cdot / \cdot$ & 91. & $r \cdot \%$ & 41. & بلى & \multirow{2}{*}{ مصرف داروى خوابآور } \\
\hline & & $\Lambda \cdot / \cdot$ & $T F /$. & $r \cdot \%$ & $r F /$. & خير & \\
\hline \multirow{2}{*}{.$/ 999$} & \multirow{2}{*}{$\cdot 1 \cdot$} & r & $\varphi /$. & r & $\varphi /$. & 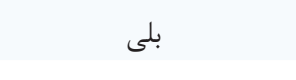 & \multirow{2}{*}{ مصرف دارو با عارضه } \\
\hline & & $\Lambda \& / \vee$ & re/. & $\Lambda \& / \vee$ & ז\&/. & خير & \\
\hline
\end{tabular}

جدول r. مشخصات دموكر افيك (متغيرهاى كمّى) بيماران در دو كَروه مداخله و كنترل

\begin{tabular}{|c|c|c|c|c|}
\hline \multirow{2}{*}{ سطح معنادارى } & \multirow{2}{*}{ آمارة آزمون } & مداخله & كنترل & \multirow{2}{*}{ متغير } \\
\hline & & انحر اف معيار & انحراف معيار & \\
\hline
\end{tabular}

\begin{tabular}{|c|c|c|c|c|c|c|}
\hline • $19 V \mathrm{~V}$ & $\cdot /$ ATd & $19 / \pi$ & $\Delta F / I T$ & $\mid r / 49$ & $\Delta \Delta / V V$ & سن \\
\hline - /AFV & $-.1199^{\mathrm{C}}$ & T/VG & $r / V \mu$ & $r / \Delta \varphi$ & $r / 9$ & فعاليت روزانه (ساعت) \\
\hline$\cdot / V \cdot 9$ & $-\cdot / T V \varepsilon$ & $19 / 10$ & $9 \Delta / I V$ & $19 / 4 F$ & GK/AT & وزن خشك \\
\hline$\cdot / 4 \Delta 1$ & $-\cdot / V \Delta Q$ & $\Delta F / T H$ & GY/9 & $\$ 9190$ & $\Delta r$ & مدتزمان شروع بيمارى كليوى (ماه) \\
\hline$\cdot 190$ & $-\cdot / \& \Delta \varphi$ & FN/AT & $F \Delta / V$ & $\mathrm{kr} / \mathrm{T}$ & $r \cdot / r r$ & مدتزمان شروع دياليز (ماه) \\
\hline.$/ 94 F$ & $\cdot / \cdot V 1$ & r/9q & $\Gamma / T V$ & $\Gamma / \Delta \varphi$ & אז/ץ & نمره به خارش بدن \\
\hline . /9V9 & $\cdot / \cdot r$ & $F / F^{\prime}$ & $\Gamma / \Lambda$ & $F / T \varphi$ & r/Ar & نمره به درد \\
\hline
\end{tabular}

جدول r. مقايسهٔ ميانغين نمرات شدت خستخى براساس يرسشنامهٔ پِايِر در حيطههاى مختلف

\begin{tabular}{|c|c|c|c|c|c|c|c|}
\hline \multirow{2}{*}{ معنادارى سطح } & \multirow{2}{*}{ آمارة آزمون } & \multicolumn{2}{|c|}{ يس از آزمون } & \multicolumn{2}{|c|}{ بيش از آزمون } & \multirow{2}{*}{\multicolumn{2}{|c|}{ نام حيطه }} \\
\hline & & انحراف معيار & ميانََين & انحراف معيار & ميانتين & & \\
\hline$\cdot / A V$ & •/VMT & $\Delta / / \Lambda$ & IV/ar & $\Delta / \Delta$ & $1 N / 14$ & كنترل & \\
\hline \multirow[t]{3}{*}{$\cdot 1 \cdot \cdots$} & $11 / 194$ & $1 / \wedge 9$ & $\Lambda / \cdot \cdot$ & $\Delta / 11$ & 19/4G & مداخله & طهُ رفتاري/ \\
\hline & & \multicolumn{2}{|c|}{$9 / 1 \wedge 9$} & \multicolumn{2}{|c|}{$-\cdot 1199$} & آمارئ آزمون t مستقل & شدت \\
\hline & & \multicolumn{2}{|c|}{$\cdot 1 \cdot$} & \multicolumn{2}{|c|}{ • } & سطح معنادارى & \\
\hline$\cdot / T \Delta \Delta$ & $-1 / 191$ & $r / r \cdot \Delta$ & $\mid 9 / 1 \ldots$ & $r / q \mu$ & $10 / \Lambda \mu$ & كنترل & \\
\hline \multirow[t]{3}{*}{$\cdot 1 \cdots$} & N/FF & T/FAF & N/r & $F / Q$ & $19 / 99$ & مداخله & حيطهُ عاطفى \\
\hline & & \multicolumn{2}{|c|}{$q / \cdot \varphi v$} & \multicolumn{2}{|c|}{.199} & آمارة آزمون t مستقل & \\
\hline & & \multicolumn{2}{|c|}{$\cdot 1 \cdots$} & \multicolumn{2}{|c|}{$\cdot|r| c \mid$} & سطح معنادارى & \\
\hline
\end{tabular}


رضا برزو و همكاران آ

\begin{tabular}{|c|c|c|c|c|c|c|c|}
\hline \multirow{2}{*}{ معنادارى سطح } & \multirow{2}{*}{ 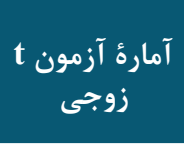 } & \multicolumn{2}{|c|}{ يس از آزمون } & \multicolumn{2}{|c|}{ ييش از آزمون } & \multirow{2}{*}{\multicolumn{2}{|c|}{ نام حيطه }} \\
\hline & & انحراف معيار & ميانگين & انحراف معيار & ميانگين & & \\
\hline$\cdot \mid \Delta \Lambda \Lambda$ & $-\cdot \mid \Delta F \Lambda$ & r/^91 & س מצח 11 & $4 / 1 / 9$ & $11 / 0$ & كنترل & \\
\hline \multirow[t]{3}{*}{$\cdot / \cdots$} & D/T & $1 / 9 \Delta 9$ & $V /$ TSV & $\Delta / \cdot F$ & $\mid r / r$ & مداخله & - يط \\
\hline & & \multicolumn{2}{|c|}{$\Delta / r \& V$} & \multicolumn{2}{|c|}{.$- \mid 9 Y \Lambda$} & آمارة آزمون t مستقل & \\
\hline & & \multicolumn{2}{|c|}{$\cdot 1 \cdots$} & \multicolumn{2}{|c|}{. IDTK } & سطح معنادارى & \\
\hline .1110 & $-1 / g T F$ & $r / r \Delta I$ & $\mid \mathrm{V} / \cdots$ & $\Delta / V \varphi 1$ & (19/4 & كنترل & \\
\hline \multirow[t]{3}{*}{$\cdot 1 \cdots$} & N/YF & T/TIT & १/१९V & $\Delta / \cdot F \mid$ & $19 / 94$ & مداخله & حيطهُ شناختى \\
\hline & & \multicolumn{2}{|c|}{ V/a\&T } & \multicolumn{2}{|c|}{$-\cdot / r \mid \Delta$} & آمارء آزمون t مستقل & خستى \\
\hline & & \multicolumn{2}{|c|}{$\cdot / \cdots$} & \multicolumn{2}{|c|}{$\cdot|A r|$} & سطح معنادارى & \\
\hline$\cdot / T Y \Lambda$ & $-|/ K M|$ & $1 r / r v q$ & GY/99V & $18 / 1 T$ & $81 / 1$ & كنترل & \\
\hline \multirow[t]{3}{*}{$\cdot / \cdots$} & $11 / \pi 1$ & ४/৭१V & l & $I F / V V$ & $9 D / T G$ & مداخله & نمرءٔ كل \\
\hline & & \multicolumn{2}{|c|}{1.1949} & \multicolumn{2}{|c|}{$-\cdot \mid \wedge 9 \Lambda$} & آمارء آزمون t مستقل & خستى \\
\hline & & \multicolumn{2}{|c|}{$\cdot / \cdots$} & \multicolumn{2}{|c|}{. / } & سطح معنادارى & \\
\hline
\end{tabular}

جدول F. مقايسُٔ ميانَين نمرات كيفيت خواب براساس يرسشنامهٔ يترزبورى در حيطههاى مختلف

\begin{tabular}{|c|c|c|c|c|c|c|c|}
\hline \multirow{2}{*}{ معنادارى سطح } & \multirow{2}{*}{ آزمون t زوجى } & \multicolumn{2}{|c|}{ بس از آزمون } & \multicolumn{2}{|c|}{ بيش از آزمون } & \multirow{2}{*}{\multicolumn{2}{|c|}{ نام حيطه }} \\
\hline & & مراف معيار & ميانتين & مراف معيار & ميانگين & & \\
\hline - MTG & 1 & $\cdot 19 \mathrm{~V}$ & $1 / 4$. & $\cdot / 1999$ & $1 / \Delta T$ & كنترل & \multirow{4}{*}{ كيفيت ذهنى خواب } \\
\hline \multirow[t]{3}{*}{$\cdot 1 \cdot r \Delta$} & T/RG & س & $1 / 14$ & $\cdot 19$ & $1 / 0$ & مداخله & \\
\hline & & \multicolumn{2}{|c|}{$1 / \Delta \wedge F$} & \multicolumn{2}{|c|}{.$/ 1 F$} & آماره آزمون t مستقل & \\
\hline & & \multicolumn{2}{|c|}{.1119} & \multicolumn{2}{|c|}{$\cdot \mid \Lambda \wedge \varepsilon$} & سطح معنادارى & \\
\hline$\cdot 19 \cdot 1$ & .1019 & l/1^ & $1 / 1$ & $1 / 1 \wedge 9$ & $1 / 1$ & كنترل & \\
\hline \multirow[t]{3}{*}{$\cdot / \cdots$} & $\varphi / \varphi \Delta \Delta$ & $\cdot / V \cdot r$ & $\cdot / V$ & l/1AF & $1 / 99$ & مداخله & \\
\hline & & \multicolumn{2}{|c|}{ F/rvi } & \multicolumn{2}{|c|}{. Ifrs } & آمارئ آزمون t مستقل & حواب \\
\hline & & \multicolumn{2}{|c|}{$\cdot / \cdots$} & \multicolumn{2}{|c|}{.1990} & سطح معنادارى & \\
\hline$\cdot / \Delta V R$ & $-\cdot|\Delta V|$ & $1 / \pi 9$ & תr/1/ & I/IVT & 11.99 & كنترل & \multirow{4}{*}{ زمان خواب } \\
\hline \multirow[t]{3}{*}{$\cdot 1 \cdot v V$} & $r / 91$ & $\cdot|9 T|$ & $\cdot / \mu \ldots$ & $1 / 1 \wedge \Lambda$ & 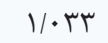 & مداخله & \\
\hline & & \multicolumn{2}{|c|}{$r / 1 \cdot 1$} & \multicolumn{2}{|c|}{$\cdot 11 \cdot 9$} & آمارة آزمون t مستقل & \\
\hline & & \multicolumn{2}{|c|}{$\cdot / \cdot r$} & \multicolumn{2}{|c|}{.$/ 914$} & سطح معنادارى & \\
\hline (TrG & 1 & $\cdot / \cdots$ & $\cdot / \ldots$ & . /NR & $\cdot / \cdot r$ & كنترل & \multirow{4}{*}{ بازدهى خواب } \\
\hline \multirow[t]{3}{*}{-} & - & $\cdot 1 \cdots$ & $\cdot 1 \cdots$ & · & - & مداخله & \\
\hline & & & & \multicolumn{2}{|c|}{.1999} & آمارةٔ آزمون t مستقل & \\
\hline & & & & \multicolumn{2}{|c|}{ •|rTI } & سطح معنادارى & \\
\hline $1 / \cdots$ & $\cdot / \cdots$ &.$|G T|$ & $1 / 9 \cdots$ & . IVTK & $1 / 9$. & كنترل & \\
\hline \multirow[t]{3}{*}{$\cdot / \cdots$} & $\varphi / 90$ & . /T\&T & $1 / \cdots$ & $\cdot 19 \vee \wedge$ & $1 / \Delta 9$ & مداخله & \\
\hline & & \multicolumn{2}{|c|}{$r / A V \mid$} & \multicolumn{2}{|c|}{$\cdot / 1 N F$} & آمارءٔ آزمون t مستقل & \\
\hline & & \multicolumn{2}{|c|}{$\cdot 1 \cdots$} & \multicolumn{2}{|c|}{$\cdot / \wedge \Delta \Delta$} & سطح معنادارى & \\
\hline
\end{tabular}




\begin{tabular}{|c|c|c|c|c|c|c|c|}
\hline \multirow{2}{*}{ معنادارى سطح } & \multirow{2}{*}{ آزمون t زوجى } & \multicolumn{2}{|c|}{ هس از آزمون } & \multicolumn{2}{|c|}{ بيش از آزمون } & \multirow{2}{*}{\multicolumn{2}{|c|}{ نام حيطه }} \\
\hline & & راف معيار & ميانَين & انحراف معيار & ميانَين & & \\
\hline .1999 & $\cdot 1 \cdots$ & 1/Tra & $\cdot / V \cdot$ & $1 / r 9$ & $\cdot / V \cdot$ & كنترل & \multirow{4}{*}{ داروى خوابآور } \\
\hline \multirow[t]{3}{*}{$.1 \cdot 19$} & $r / \Delta F$. & $\cdot / 4 \cdot r$ & $\cdot 11 \ldots$ & $1 / T r$ & . & مداخله & \\
\hline & & \multicolumn{2}{|c|}{ T/DTA } & \multicolumn{2}{|c|}{$\cdot / \mu \cdot \Lambda$} & آمارئ آزمون t مستقل & \\
\hline & & \multicolumn{2}{|c|}{$.1 \cdot 1 \mathrm{~F}$} & \multicolumn{2}{|c|}{$\cdot / V \Delta q$} & سطح معنادارى & \\
\hline . I99T & $-\cdot|y|$ & $1 / \cdots$ & $1 / 0 \cdots$ & $1 / 1 r$ & $1 / 49$ & كنترل & \\
\hline \multirow[t]{3}{*}{$\cdot 1 \cdots$} & $p / \cdot q$. & $\cdot / \mathrm{A} \mid \mathrm{V}$ & •/VGG & $1 / 1 r$ & $1 / 0$ & مداخله & \\
\hline & & \multicolumn{2}{|c|}{$r / \cdot q f$} & \multicolumn{2}{|c|}{$-.111 f$} & آمارة آزمون t مستقل & \\
\hline & & \multicolumn{2}{|c|}{$\cdot / \cdot r$} & \multicolumn{2}{|c|}{.191} & سطح معنادارى & \\
\hline$\cdot \mid \Lambda \cdot q^{f}$ & $\cdot / \pi \Delta$ & $r / \Delta r$ & אוr/IN & $F / r \Lambda$ & $\Lambda / r$. & كنترل & \\
\hline \multirow[t]{3}{*}{$\cdot 1 \cdots$} & $\Delta / V \varphi$ & $1 / \Delta r$ & $1 / 4$ & $r / 9 F$ & N/VG & مداخله & \\
\hline & & \multicolumn{2}{|c|}{ D/VMG } & \multicolumn{2}{|c|}{ (r/r } & آمارة آزمون t مستقل & 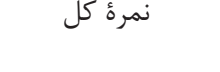 \\
\hline & & \multicolumn{2}{|c|}{$\cdot / \cdots$} & \multicolumn{2}{|c|}{$\cdot / V \Delta \Delta$} & سطح معنادارى & \\
\hline
\end{tabular}

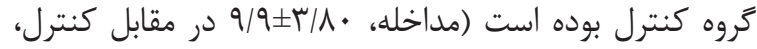

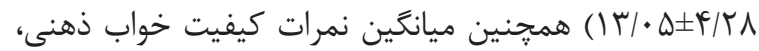

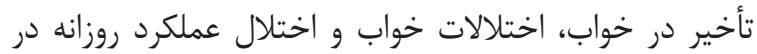

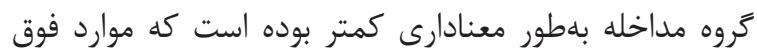

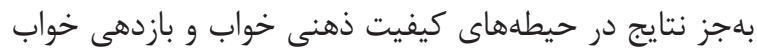

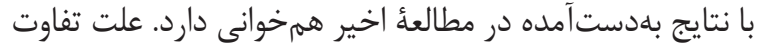

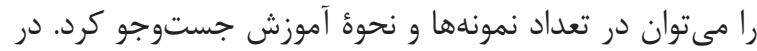

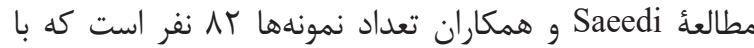

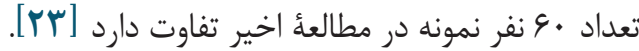

همجنين يافتههاى مطالعة اخير مشابه نتايج ساير

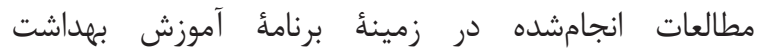

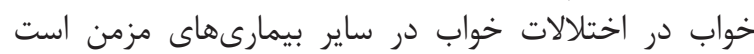

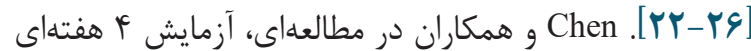

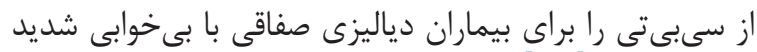

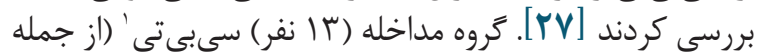

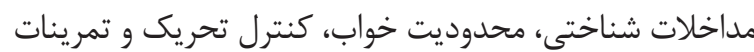

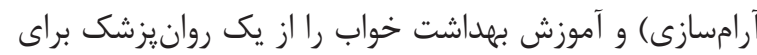

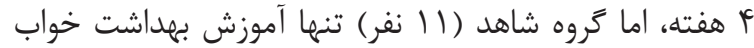

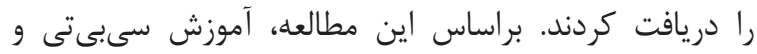

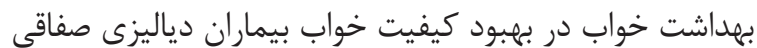

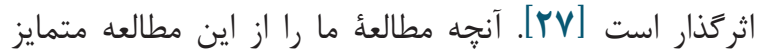

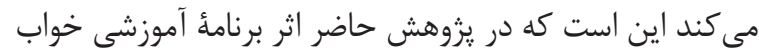

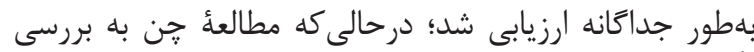

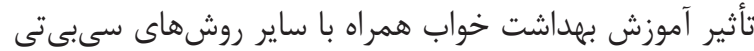

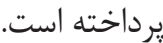

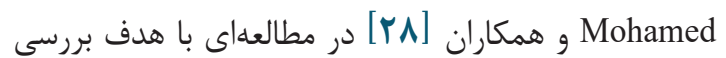

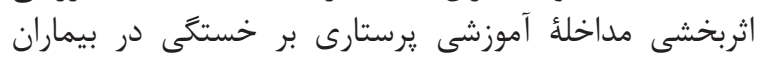

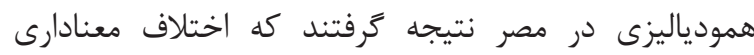

1. Cognitive Behavioral Therapy

دورئ TV شمارة I - فروردين و ارديبهشت

\section{بحثث}

در اين مطالعه، تأثير برنامهٔ آموزشى بهداشت خواب بر

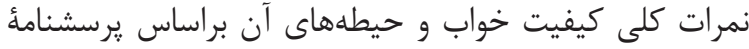

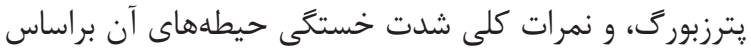

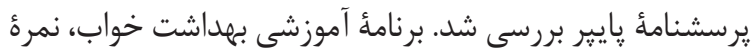

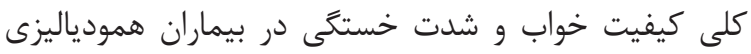

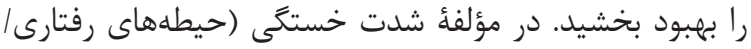

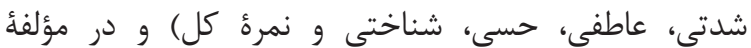

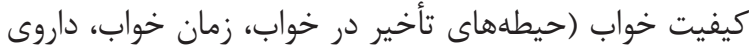

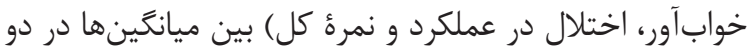

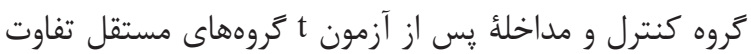
معنادارى وجود دارد.

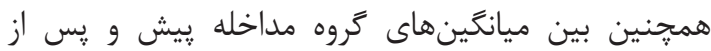

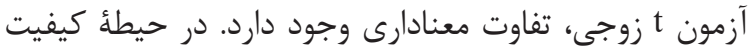

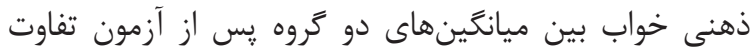

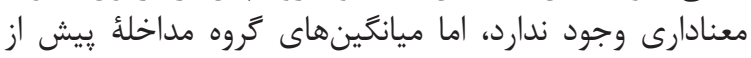

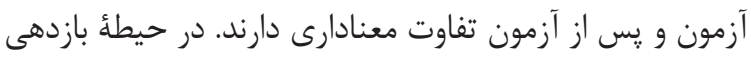

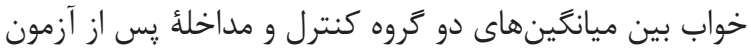

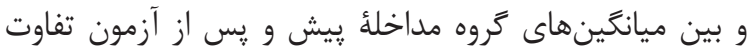

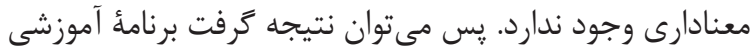

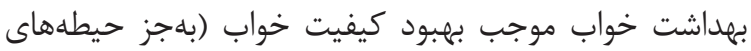

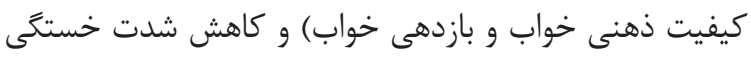

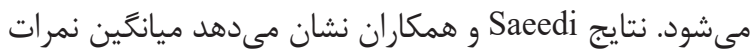

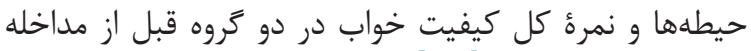
تفاوت معنادارى ندارد [بr.

ميانگين نمره كيفيت خواب گروه مداخله گِ يس از آموزش

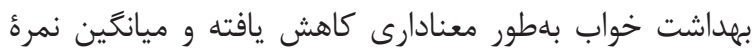

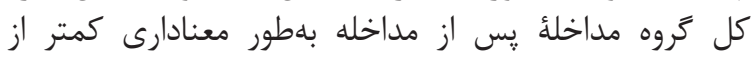




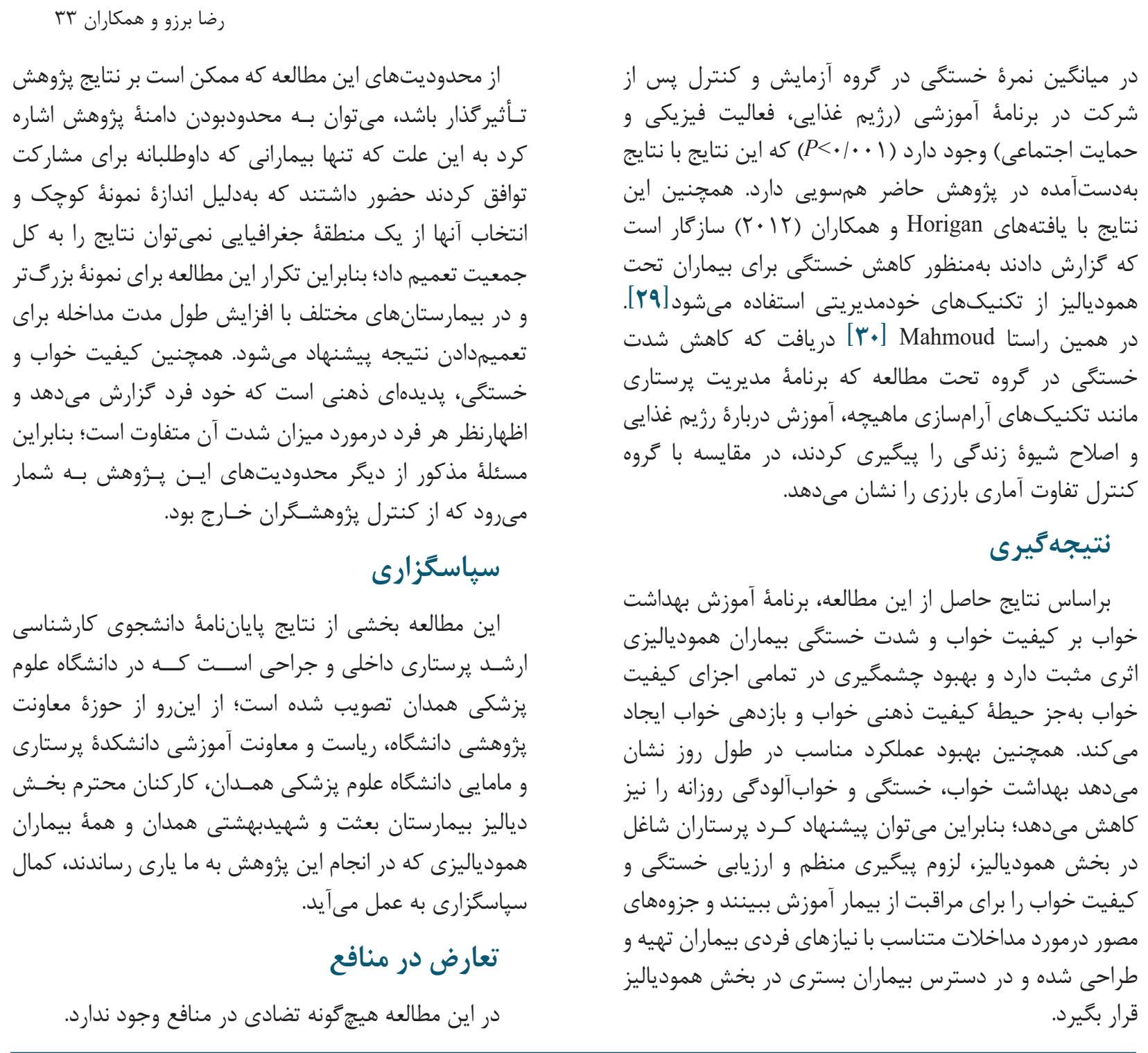

\section{References}

1. Levey AS, De Jong PE, Coresh J, Nahas ME, Astor BC, Matsushita K, et al. The definition, classification, and prognosis of chronic kidney disease: a KDIGO Controversies Conference report. Kidney international. 2011; 80(1):17-28.

2. Tayebi A, Babajani M, Sadghisharme M, Ebadi A, Eynallahi B. The effect of hatha yoga exercises on dialysis adequacy. Journal of Critical Care Nursing. 2012; 4(4):90-183.

3. Farmahin H, Farahani B, Sajadi A, Esmaeypourzanjani A, Dormanesh B, Zare M. Valuate the effect of vitamin $C$ Fatigue in patients with chronic renal failure undergoing hemodialysis feed in selected hospitals to Military Medical University. Journal of the Islamic Republic of Iran University of Medical Sciences. 2010; 7(3):8-163.

4. Jhamb M, Pike F, Ramer S, Argyropoulos C, Steel J, Dew M, et al. Impact of fatigue on outcome in the hemodialysis study. American Journal of Nephrology. 2011; 33(6):523-515. https:// doi.org/10.1159/000328004

5. Sajadi A, FarmahiniFarahani B, EsmaeilpoorZanjani S, Durmanesh B, Zare M. Effective factors on fatigue in patients with chronic renal failure undergoing hemodialysis. Iranian Journal of Critical Care Nursing. 2010; 3(1):33-8.

6. Shaer Moghadam S, Shahdadi H, MohamadPour R, Shamsizadeh M, AL E. The Effect of Hand Reflexology on Fatigue in Patients Undergoing Hemodialysis. International Journal of Basic Science in Medicine. 2015; 8(1):1-10.

7. Rejeh N, Hearavi-Karimoo M, Bahrami T, Raeesi M, Tadrisi D. The assessment of factors affecting fatigue in older people with hemodialysis. Iranian Journal of Nursing Research. 2015; 10(3):10817.

8. Hadian J, Aliasgharpoor M. Evaluating the effects of designed exercise program on mean of activity tolerance in hemodialysis patients. Journal of Shahrekord University of Medical Sciences. 2012; 14(5):83-91.

9. Borzou S, Farghadani F, Oshvandi K, Gholyaf M, 
Mahjub H. Effect of cool dialysate on vital signs, comfort and adequacyof dialysis in hemodialysis patients. Journal of Holistic Nursing and Midwifery. 2013; 25(77):9-16.

10. Araste M, Yosefi F, Sharifi Z. Evaluation of sleep quality and its effective factors in patients admitted to gynecology and general surgery. Medical Journal of Mashhad University of Medical Sciences. 2013; 57(6):762-769.

11. Shiri H, Mazaheri K, Abed Saeedi Z, Alavi Majd H. Sleep disturbances and sleep hygiene in hemodialysis patients at hospitals affiliated to Shaheed Beheshti Medical University. Faculty of Nursing and Midwifery Quarterly. 2006; 16(53):11-18.

12. Izadi Avanji F S, Adib Hajbaghery M, Afazel M R. Quality of sleep and it's related factors in the hospitalized elderly patients of Kashan hospitals in 2007. Feyz. 2009; 12(4):52-60

13. AhmadzadehVosta H, Hosseini R, Sanei H. The Relationships Between Sleep Habits and Times With Sleep Quality Among College Students. Journal of Ilam University of Medical Sciences. 2013; 21:273-283.

14. Rusterholz T, Achermann P. Topographical aspects in the dynamics of sleep homeostasis in young men: Individual patterns. BMC Neurosci. 2011; 12:84-89. https://doi.org/10.1186/14712202-12-84

15. Dikelmann S, Born J. The memory function of sleep. Nature Reviews Neuroscience. 2010; 11:114-126.

16. Sato M, Yamadera W, Matsushima M, Itoh H, Nakayama K. Clinical efficacy of individual cognitive behavior therapy for psychophysiological insomnia in 20 outpatients. Psychiatry and Clinical Neurosciences. 2010; 64:187-195. https://doi. org/10.1111/j.1440-1819.2009.02060.x

17. Jefferson C, Drake C, Scofield H. Sleep hygiene practices in a population-based sample of insomniacs. Sleep. 2005; 28(61):1-5. https://doi. org/10.1093/sleep/28.5.611

18. Saeedi M, Shamsikhani S, Farahani PV, Haghverdi F. Sleep Hygiene Training Program for Patients on Hemodialysis. Iranian Journal of Kidney Diseases. 2014; 8(1):65-9.

19. Asgarpoor AF, Amini Z, Zeraati A, Esmaeli H. The effect of a care plan based on the Roy Adaptation Model on level of Fatigue in hemodialysis patients. Journal of Evidence-based Care Evidence Based Care. 2011; 1(1):77-90.

20. Piper BE, LDibble S, Dodd MG, Weiss MC, Slaughter RE, Paul SM. The revised piper fatigue scale: Psychometric in evaluation in women with breast cancer. Oncology Nursing Forum. 1998;
Fr بر برسى تأثير آموزش بهداشت خواب بر شدت خستگى ...

25:677-684. https://doi.org/10.1037/t18854-000

21. Buysse D, Reynolds I, Monk T, Berman S, Kupfer D. The Pittsburgh sleep quality index: A new instrument for psychiatric practice and research. Psychiatry Research. 1989; 28(2):193-213. https://doi.org/10.1016/0165-1781(89)90047-4

22. Berger AM, Kuhn BR, Farr LA, Lynch JC, Agrawal S, Chamberlain J, Von Essen SG. Behavioral therapy intervention trial to improve sleep quality and cancer-related fatigue. PsychoOncology: Journal of the Psychological, Social and Behavioral Dimensions of Cancer. 2009; 18(6):634-646.

23. Saeedi M, Ashktorab T, Saatchi K, Zayeri F, Amir Ali Akbari S. The effect of progressive muscle relaxation on sleep quality of patients undergoing hemodialysis. Iranian Journal of Critical Care Nursing. 2012; 5(1):23-28.

24. Cohen L, Warneke C, Fouladi RT, Rodriguez MA, Chaoul-Reich A. Psychological adjustment and sleep quality in a randomized trial of the effects of a Tibetan yoga intervention in patients with lymphoma. Cancer. 2004; 100:2253-2260. https://doi.org/10.1002/cncr.20236

25. Simeit R, Deck R, Conta-Marx B. Sleep management training for cancer patients with insomnia. Support Care Cancer. 2004; 12:176-183. https:// doi.org/10.1007/s00520-004-0594-5

26. Pedram Razi S, Varaei S, Kazemnejad A, Bagheri F. The Effect of Foot Reflexology Massage on Sleep Quality in Women With Type 2 Diabetes; a Clinical Study. Avicenna Journal of Nursing and Midfery Care. 2018; 26(5):283-289. http://nmj. umsha.ac.ir/article-1-1813-en.html

27. Chen HY, Chiang CK, Wang HH, Hung KY, Lee YJ, Peng YS, et al. Cognitive-behavioral therapy for sleep disturbance in patients undergoing peritoneal dialysis: A pilot randomized controlled trial. American Journal of Kidney Diseases. 2008; 52(2):314-323.

28. Mohamed SA. The effectiveness of an educational intervention on fatigue in hemodialysis patients: a randomized controlled trial. Journal of Nursing and Health Sciences. 2014; 3(4):40-50.

29. Horigan AE. Fatigue in hemodialysis patients: a review of current knowledge. Journal of pain and symptom management. 2012; 44(5):715-724.

30. Mahmoud F. Breast Cancer (MD) Advanced and Traditional Imaging Modalities. Ain Shams Medical Journal. 2002; 53(1):1. 